\title{
Indonesian New Normal Mathematics Education - Seeking Certainty in Uncertain Times
}

\author{
Allan Leslie White ${ }^{1, *}$ \\ ${ }^{1}$ University of Western Sydney, Australia; \\ ${ }^{1}$ Research Fellow SEAMEO \\ *Corresponding author. Email: allan.white6@gmail.com
}

\begin{abstract}
Humanity has dealt with pandemics or plagues throughout history. History also demonstrates that in periods of uncertainty there are always guides that remain certain. In response to Covid-19, the Indonesian government's 'New Normal' provided a list of challenges for all educators, who must then adapt their resources and pedagogical strategies to meet these challenges. Yet, from the 'Old Normal' what remains a certainty for educators amongst all the chaos of pandemic change? This paper discusses the pedagogical norms that research has provided regarding the teaching and learning process for mathematics at all levels. It argues that these norms provide certainty for educators in their planning and delivery irrespective of resources, context, or online capacity. It is by following these norms that educators will improve mathematics skills for 'New Normal' education. Whether the responses to the New Normal are to become successful depends greatly upon the adaptability and dedication of these educators, who should be regarded as 'super heroes' or 'national treasures'.
\end{abstract}

Keywords: New Normal, Mathematics Education.

\section{INTRODUCTION}

Humans from very early beginnings have struggled with the chaos present in their world and with the uncertainty of changing circumstances. The prehistoric world was a fearful place with uncertainty of seasons, weather, and habitat, and all posing threats to human existence. The development of language and mathematics are but two examples of humanity's attempts to impose order and certainty upon this frightening and uncertain world.

Currently our world has also been thrown into greater uncertainty due to the Coronavirus (COVID-19) which has disrupted the global educational systems with approximately 1.7 billion learners impacted by educational system closures. The pandemic. has created 'New Normal' ways of life and Indonesia was not spared this deadly virus. The Indonesian government responded with a joint ministerial decree that has caused considerable discussion and comment, particularly among educators. The Federation of Indonesian Teachers Associations responded and conducted a survey that revealed more than half of the schools across the country stated they were not ready to resume face-to-face learning due to a lack of infrastructure and funding [1].
Educators have scrambled to reorganize and learn how to conduct hybrid, blended, or fully online learning classes. The challenges upon educators have been very demanding and diverse due to the great range of resources and learning environments. For example, there are now health and safety issues around the interaction between educators and learners and among learners themselves. For educators, with everything seemingly changing, what remains of the 'Old Normal' that is still certain and useful in the New Normal?

This paper will not examine health and safety issues, technical aspects of technology, nor will it focus on the administrative uncertainties that have arisen because of the pandemic. It will explore the implications of the 'New Normal' for the teaching and learning of mathematics by attempting to articulate what elements of the 'Old Normal' provide certainty for educators and learners and are the core elements of the teaching and learning process.

It is often stated that the guide to the future lies in the past and a very brief selective time-travel will show that while periods of uncertainty have continually existed throughout human history, they have been accompanied 
by certainties through which humanity was able to progress.

\subsection{Second Level Heading (Head 2)}

First, confirm that you have the correct template for your paper size. This template has been tailored for output on the A4 paper size.

In this template, the "Styles" menu should be used to format your text if needed. Highlight the text you want to designate with a certain style, and then select the appropriate name on the Style menu. The style will adjust your fonts and line spacing. Use italics for emphasis; do not underline. To insert images in Word, position the cursor at the insertion point and either use Insert | Picture | From File or copy the image to the Windows clipboard.

\subsubsection{Third Level Heading (Head 3)}

Headings may be numbered or unnumbered ("1 Introduction" and "1.2 Numbered level 2 head"), with no ending punctuation. As demonstrated in this document, the initial paragraph after a heading is not indented.

\subsubsection{Fourth Level Heading}

This is a fourth level heading. You can replicate it where suitable.

\section{A BRIEF TIME-TRAVEL OF UNCERTAINTY AND CERTAINTY}

Periods of uncertainty have been a constant disruption to humanity, to education and to the development of mathematics. Consider the ancient Greek philosopher Heraclitus who lived in Ephesus (now modern Turkey) and was active around 500 BCE. So concerned was he with the uncertainties of his time that he produced a statement, subject to considerable debate, that 'All is flux'. Loosely translated and understood as 'everything is changing'. Logically having a rule (everything changes) that doesn't change is a contradiction. Leaving aside the debate over Heraclitus' comparison of all existing things with the flow of a river, whereby no-one could step twice into the same river. In the world of Heraclitus, while it seemed to be always changing and uncertain, there were still rules that remained certain.

Making a huge jump across time to 1980, Professor Morris Kline released his book titled: 'Mathematics: The Loss of Certainty' [2]. In part it describes the impact upon 19th century mathematicians of the development of the non-Euclidean geometries. Imagine the shock if you were certain that the universe was based on Euclidean principles (God the Mathematician) only to discover that there were other ways of understanding this universe mathematically. Again, leaving aside the debate over the book, it indicates a time when mathematical certainty became uncertain and yet within each mathematical system, certainty was possible. In the Euclidean world, the sum of the angles of a triangle was still 180 degrees. It just wasn't so in other systems such as spherical geometry.

My final example involves a consideration of timetravel itself and a long-held desire to go back in time to control specific current changes. The 'grandfather paradox' asks what happens if you travel back in time and kill your grandfather? If you do, you cease to exist, but then if you never existed then you couldn't kill your grandfather. This is clearly a paradox. So the question that troubled mathematicians was, can a time-traveler act freely? A 2020 mathematical paper [3] has contributed to accepted time-travel theory by showing that a person travelling from the present to the past would still be able to act freely without creating paradoxes. The researchers gave an example of someone travelling back in time to stop the current pandemic. Before their research findings were released, current theory felt it would be impossible to stop the original first person contracting the virus and so preventing the spread. Under this new model it would be possible to prevent the specific first person from contracting the virus, but the pandemic would still occur through other means such as a different person would get sick, the time traveler would get sick, or something else. The pandemic would remain a certainty.

This brief time-travel illustrates that in uncertain times there are still certainties, so what certainties can educators use during the New Normal?

\section{UNCERTAINTY AND CERTAINTY RESULTING FROM THE NEW NORMAL IN INDONESIAN EDUCATION}

The 'New Normal' provides a list of challenges for educators, who must adapt their resources and pedagogical strategies to meet these challenges. The consequence of the sheer size of Indonesia results in a great variation in the resources available to educators and their students. Access to technology is only one variable. For some, technology pressures educators into using an 'Old Normal' 'stand and deliver' pedagogy (sometimes called chalk and talk) rather than assisting students to engage with and understand the mathematics. So, in spite of this great diversity in resources, the manner in which educators adapt their responses needs to be guided by a core of certainty. Luckily there are core pedagogical principles that can act as guides for educators.

The National Council of Teachers of Mathematics (NCTM) along with Professor Boaler and her team from Stanford University have provided creative leadership in recent worldwide mathematics education and research. NCTM released their principles [4], listing eight research-informed classroom actions, based on the Council's core principles and intended for educators of 
mathematics. Resonating with these principles, Boaler and her team released a statement listing seven positive norms essential for mathematics teaching and learning [5].

The aim for the rest of this paper is to discuss how Boaler's seven norms form a pedagogical body of certainty for educators when responding to the uncertainties of the pandemic. These norms are not mutually exclusive and in fact work in concert with each other. Because of size limitations of this paper, I will omit many of the links between norms and leave that task to the reader.

\subsection{Norm 1: Everyone can learn mathematics to the highest levels}

This section focuses upon students' attitudes and beliefs. A certainty is that achievement excellence is enhanced by developing the students' beliefs that they can achieve at any level of mathematics, and there is no such thing as a born mathematics person.

There is a growing body of research, including brain research that regards children as having the potential to learn anything [6]. The level of attainment depends upon how the children are nurtured, encouraged, and challenged. These are the responsibilities of parents, teachers and the wider society. Researchers acknowledge there are brain differences present at birth, yet they attribute greater importance to the learning experiences after birth, for any excellence shown later in the children's lives. So, there is a need for parents, teachers and the wider society to promote this message to students as well as providing a safe and challenging learning environment.

If beliefs are important, how do researchers explain how they work? Psychologist Carol Dweck [7] conducted research into students' orientation to learning in terms of whether they held either mastery goals or performance goals. She reported a distinction between what were labelled as a fixed mindset and as a growth mindset. A fixed mindset focuses on performance and the student belief that while s/he can learn things, s/he cannot become more intelligent. Whereas students with a growth mindset focus on understanding the content and evaluating success against their ability to use and transfer their knowledge. The student believes s/he can change their brain and become smarter through hard work and struggle. These students have a more resilient response to failure, they remain focused on mastering skills and knowledge even when challenged, and they do not see failure as an indictment of themselves [8].

Research also points to the manner in which parents, teachers and the wider society should encourage students to believe they can learn and master anything (including mathematics) by their effort and struggle and that is through appropriate and consistent feedback.
What determines whether feedback is appropriate depends upon the target of the feedback. If a student demonstrates high achievement then the feedback should be aimed at the work, the thinking, the effort and the struggle and not at the personal traits of the student [9].

It turns out that even believing you are smart - one of the fixed mindset messages - is damaging, as students with this fixed mindset are less willing to try more challenging work or subjects because they are afraid of slipping up and no longer being seen as smart. Students with a growth mindset take on hard work, and they view mistakes as a challenge and motivation to do more [10].

So appropriate feedback targets the behaviour and not the person. "I am really proud of how hard you have worked" or "good thinking" instead of "clever girl" or "smart boy". A review of 131 well-designed studies in educational and workplace settings found that feedback makes performance worse when it is focused on the selfesteem or self-image. The use of feedback improves performance when it is focused on what needs to be done to improve, and particularly when it gives specific details about how to improve [11].

Appropriate feedback should be a pedagogical certainty for mathematics teaching. Whether students are back in class or confined to their homes, encouragement is needed to develop their growth mindset so they become hardworking and resilient learners.

\subsection{Norm 2: Mistakes are valuable}

This area lies in the affective domain and is concerned with educators creating safe learning environments where students feel safe enough to venture opinions, to make mistakes, to ask questions and know that they will not be ridiculed or judged as stupid. In this safe learning environment, mistakes become regarded as learning opportunities. The aim for educators is to help and encourage their students to overcome and learn from their errors. Creativity requires taking risks and making mistakes. Research shows that the brain improves and grows through concentration and challenge. When students struggle and make mistakes, synapses fire and their brains grow [12]. Some parts of scientific knowledge are built upon a process of making mistakes and learning from them until a series of experiments produces a useable result.

Researchers [13] used an EEG to measure and track electrical impulses of college students' brain activity as each worked through either standard mathematics problems or mathematical Mindset problems based upon Boaler's design [14]. In complete contrast to the standard problem group, the Mindset problem group became more motivated and engaged as they worked. Engaging the brain's stimuli reward pathways by making simple changes to how mathematical problems are presented, makes it possible to increase the motivation of mathematical learners. 
The implications for teaching and learning are important to the manner of support given to students. Scaffolding developed in the late 1950 s by Jerome Bruner was intended to support students during the learning process by the teacher adjusting the support to the needs of the student with the intention of helping the student achieve certain learning goals. The main goal was to help students face and overcome challenges through struggle and encouragement, and not have teachers remove the challenge or only give the students easy challenges to solve. Thus, scaffolding should allow students to make mistakes and to learn from their mistakes in order to overcome their challenges and thus encouraging them to develop growth mindsets, Boaler recommended the use of sayings such as: "easy is a waste of time", "working hard grows your brain", "it is really important to make mistakes". [15]

\subsection{Norm 3: Questions are really important}

This section discusses questions that support learning arising from the cognitive domain and questions that students ask arising from the affective domain.

Teachers use many different types of questions depending on the goals of the questions. For example, a teacher may use questions as a classroom management device. By scattering questions among the students, the questions become a way of keeping the class on task, and engaged. This may keep many of the students focused but it does very little in supporting thinking. How much time a teacher allows a student to respond before evaluating their response is also important and contributes to a safe learning environment. So, what questions support learning?

Questions that support learning may give us a window into student thinking or they will challenge the student's thinking. There is research that has revealed it is essential that teachers explore students' thinking before assuming that students have 'understood' something.

By asking questions of students, teachers try to establish whether students have understood what they are meant to be learning, and if students answer the questions correctly, it is tempting to assume that the students' conceptions match those of the teacher. However, all that has really been established is that the students' conceptions fit, within the limitations of the questions. [16]

Research has revealed that as students move through school, they ask fewer and fewer questions, for fear of being ridiculed. Providing a safe learning environment is needed as there is substantial evidence that students' learning is enhanced by encouraging them to generate their own questions [17].

\subsection{Norm 4: Mathematics is about creativity and making sense}

Earlier in this paper creativity was linked to encouraging students to take risks, make mistakes and see these mistakes as learning opportunities. Creativity is also linked to challenge, struggle and a growth mindset. Mathematics should be presented as a very creative subject that involves visualizing patterns and creating solutions that others can understand. Within the students' creative thinking process the creation of meaning is crucial [18]. Understanding, making sense or making meaning determines the possibility that what is learned will be retained in the long-term memory, which is a goal of mathematics teaching and learning. It involves a process of an increasing accumulation of stimulation and connection.

Students may diligently follow the teacher's instructions to memorize facts or perform a sequence of tasks repeatedly, and may even get the correct answers. But if they have not found meaning by the end of the learning episode, there is little likelihood of long-term storage. [19]

Research conducted by Skemp [20] resulted in the clarification of teachers' use of the word understanding, where instrumental mathematical understanding was described as 'rules without reasons' or knowing how or what to do to get an answer, whereas relational understanding was concerned with meaning and knowing both what to do and why it is being done to get an answer. Skemp [21] discussed the development of schemas as evidence of the construction of relational understanding and this resonates very strongly with the structure of the connections within the brain and with the research literature on 'connected knowledge'.

\subsection{Norm 5: Mathematics is about connections and communicating}

The relationship between teacher and learner plays a crucial part in the learning process. For example, an ongoing longitudinal study involving 4169 children aged 10-11 years and 3343 teachers examined the relationship between the student gender and teacher, qualities of the student-teacher relationship, and students' self- concept [22]. The study reported that with boys, closeness with their teachers did not predict their self-concept although conflict in their relationships negatively affected selfconcept. Whereas with girls, both closeness and conflict predicted self-concept, with conflict having a greater effect on self-concept than closeness.

The earlier norms involving growth mindset, treatment of mistakes, challenge and others all play a part in the communication process and learning.

Students can grasp high-level ideas, but they will not develop the brain connections that allow them to do so if 
they are given low-level work and negative messages about their own potential. [23]

Extending the previous norm involving understanding, the interplay of the instrumental and relational aspects of understanding leads to what is often termed compression, where the brain forms more complex and efficient neural networks. Mathematics is amazingly compressible. A student may struggle with a mathematical concept over a long time, working through a step by step process, and working from several approaches. This may develop in the student's brain, the mental perspective to see the steps as a whole, which is the result of a tremendous mental compression. The student is now able to file it away, recall it quickly and completely when needed, and use it as just one step in some other mental process.

The insight that goes with this compression is one of the real joys of mathematics [24]. An insight seems to result from a connective process within the brain or a quick restructuring that produces new understanding that is a compression of the connected information. An insight is not an end in itself but can contribute to further understanding and further insight. A student in year 7 understands Pythagoras' theorem as relating to the area of squares on the sides of a right-triangle. In year 8 the student discovers that any shape (eg. semi-circles) used on all sides will work as the theorem depends upon area which is measured in square units. Later in year 10, the same student may develop a further insight where Pythagoras' theorem is seen a unique specific example (one angle equal to 90 degrees) of the more general rule known as the cosine rule (for any angles).

It is the accumulation of insights that leads to further compression of mathematical understanding. This compression provides the mathematical tools to efficiently tackle more sophisticated and complicated mathematical problems. Thus, encouraging student insight and communication should be goals in the process of teaching for understanding

\subsection{Norm 6: Depth is more important than speed}

A student's ability to recall or answer quickly poses a difficulty for teachers [25]. Does it signal that the student has a deep understanding of compressed insights and concepts or does it signal something that it has been memorized and may not signal understanding?

When a student learns a new concept, an electric signal sparks, cutting across synapses and connecting different parts of the brain and forms networks of neurons that fire together. If the child learns a concept deeply, then the synaptic activity creates lasting connections in the child's brain (long term memory), whereas surface learning quickly decays. This key ability to grow and decay has been termed 'brain plasticity' or 'neuroplasticity'. Research has shown that the brain can reorganize itself in remarkable ways as a result of a change in stimuli. It is essentially a process of rewiring the brain by forming or strengthening new connections and allowing old connections to decay. The more a student uses these networks the more developed they become until eventually they become automatic and can be recalled quickly. If certain networks are not used then they decay and eventually disappear so something that is just memorized is quickly forgotten without constant revision.

Carpenter and Lehrer identified the types of brain activity required and described five forms of mental activity that assisted students to gain deeper mathematical understanding. They characterized understanding as a dynamic process that emerges in learners with the following interrelated forms: (a) constructing relationships, (b) extending and applying mathematical knowledge, (c) reflecting about experiences, (d) articulating what one knows, and (e) making mathematical knowledge one's own [26].

A study of 83 Grades 7 and 8 American students who completed a test comprising items taken from the Illinois Standards Achievement Tests reported that students' scores on tests do not necessarily reflect their level of understanding of mathematical concepts and relationships. Results indicated a $35 \%$ mismatch with students who in spite of giving the correct answers demonstrated little or no understanding while other students who gave incorrect answers when interviewed demonstrated some understanding [27].

A study involving year 9 students across the range of abilities, and the results for low performing students challenged the use of the term misconception for many of the students' errors. A misconception can be regarded as a fairly stable, but inappropriate, way of thinking ... analysing the errors made by low performers in this study, was that the word 'stable' was not one that could sensibly be used [28]. Students with 'unstable' conceptions will give different answers at different times and hence it is possible that their test scores will rise or decline based on luck. Students who have not developed confidence in their ability to answer a question may revert to guessing. This may well explain the $35 \%$ mismatch with students who gave correct answers with little or no understanding and others who gave incorrect answers but possessed some understanding reported in Ellerton and Olson's [27] study.

In the cycle of teaching and learning mathematics, assessment is a central component for teachers' decisions. So how do teachers determine if answers are based upon understanding? The type of assessment was the focus of a study that completed a review of 250 studies from around the world, published between 1987 and 1998 [29]. The review supported earlier studies which reported that a focus by teachers on assessment for learning, as opposed to assessment of learning, produced a substantial increase in students' achievement [30]. 


\subsection{Norm 7: The Mathematics class is about learning not performing}

From the previous norm, classroom drill and practice of mathematics using only memorization was regarded as a poor strategy. Better teaching strategies of practice are needed to enhance student understanding. Being able to perform by quickly reciting mathematical facts is of no use if there is no understanding of the application or the underlying conceptual structure of the facts. So how do teachers ensure that students use their neural networks to become more developed through regular use?

Sousa [31] contrasts two kinds of rehearsal practices as rote and elaborative depending upon their effects upon the brain. Rote rehearsal is a process of learning information in a fixed way using memory and without meaning, and is easily forgotten. Cramming for examinations is a form of rote rehearsal, which usually occurs in a brief intense time period just before an examination, where material is crammed into the working memory, but is quickly forgotten without further sustained practice. There is no sense making and so it never makes it into the long-term memory.

Elaborative rehearsal encourages learners to form links between new and prior learning, to detect patterns and relationships and to construct meaning or connected knowledge. The construction of meaning involves the building of cognitive schemas that will assist long term memory. Elaborative rehearsal leads to meaningful, longterm learning. There are a range of elaborative rehearsal teaching strategies that differ in success. The successful ones involve distributed practice that is sustained practice over time, building understanding and resulting in longterm storage. Distributive practice resonates very strongly with the East Asian Repetitive Learning which is often misunderstood as a form of rote, but is a process of continuous practice with increasing variation as a route to understanding and procedural proficiency by providing challenges suited to the ability of the student [32].

\section{CONCLUSION}

This paper has sought to discuss the norms that research has provided for the teaching and learning process of mathematics at all levels. It was argued that these norms provide certainty for educators in their planning of strategies that encourage their students to accept challenge, to build their deep understanding, to acquire skills to question and communicate, to develop links and connections within their knowledge, and to develop positive attitudes towards their learning and knowledge. It relies upon educators adapting these norms to their context and resources. By following these norms, educators will improve students' mathematics skills for the 'New Normal' education.
This adaption process highlights the complexity faced by educators who are expected to remain at the front line of change and deal with the consequences of this change, and take on the demands and uncertainties of the pandemic. The 'New Normal' statement was an attempt by the Indonesian government to create greater certainty, but whether it will be successful depends upon the adaptability and dedication of the Indonesian educators. It is this dedication and selfless service by Indonesian educators to their students that motivated the author to write elsewhere that they should be regarded as 'national treasures' and 'super heroes' [33].

\section{REFERENCES}

[1] Jakarta Post 2020, June 16 Indonesian schools not ready for 'new normal': Survey. Retrieved from: https://www.thejakartapost.com/news/2020/06/16/i ndonesian-schools-not-ready-for-new-normalsurvey.html

[2] Kline, M 1980 Mathematics: The loss of certainty (London: Oxford University Press)

[3] Tobar, G and Costa, F 2020 Reversible dynamics with closed time-like curves and freedom of choice. J Classical and Quantum Gravity, 37, 205011 pp 18 https://doi.org/10.1088/1361-6382/aba4bc

[4] National Council of Teachers of Mathematics (NCTM) 2014 Principles to actions: Ensuring mathematical success for all (Reston, VA: Author)

[5] Boaler, J 2015 Setting up Positive Norms in Math Class. Youcubed. Retrieved from: https://www.youcubed.org/wpcontent/uploads/2017/03/Norms-Paper-2015.pdf.

[6] Boaler, J 2016 Mathematical Mindsets (San Francisco CA: Jossey-Bass)

Chestnut, E, Lei, R, Leslie, S-J, \& Cimpian, A 2018 The Myth That Only Brilliant People Are Good at Math and Its Implications for Diversity. Education Sciences, 8265 MDPI AG. Retrieved from http://dx.doi.org/10.3390/educsci8020065

Doidge, N 2008 The brain that changes itself: Stories of personal triumph from the frontiers of brain science (Rev Ed) (Melbourne: Scribe Publications Pty Ltd)

[7] Dweck, C S 2006 Mindset: the new psych of success (New York: Ballantine Books)

[8] Daly, I, Bourgaize, J, and Vernitski, A 2019 Mathematical Mindsets Increase Student Motivation: Evidence from the EEG. Trends in Neuroscience and Ed, 15, 18-28

[9] Butler, R 1987 Task-involving and ego-involving properties of evaluation: Effects of different 
feedback conditions on motivational perceptions, interest, and performance. J Ed Psych, 794474 482. https://doi.org/10.1037/0022-0663.79.4.474

[10] Boaler, J 2016 Mathematical Mindsets (San Francisco CA: Jossey-Bass) p 7

[11] Wiliam, D 2005 Keeping learning on track: Formative assessment and the regulation of learning. Making Mathematics Vital: Proc of the Twentieth Biennial Conf of The Aust Assoc of Math Teachers pp. $20-34$ Retrieved from: https://scholar.google.com.au/scholar?q=Wiliam+ $\% 282005 \% 29 \& \mathrm{hl}=\mathrm{en} \& a s_{-}$sdt $=0 \% 2 \mathrm{C} 5 \&$ as_vis $=1 \&$ as_ylo $=2004 \&$ as_yhi $=2005$.

[12] Boaler, J 2015: Rev ed What's math got to do with it? How teachers and students can transform mathematics learning and inspire success (New York: Penguin Books)

[13] Daly, I, Bourgaize, J and Vernitski, A 2019 Mathematical Mindsets Increase Student Motivation: Evidence from the EEG. Trends in Neuroscience and Ed, 15, 18-28.

[14] Boaler, J 2016 Mathematical Mindsets (San Francisco CA: Jossey-Bass) pp 57-91.

[15] Boaler, J 2015 Setting up Positive Norms in Math Class. Youcubed. Retrieved from: https://www.youcubed.org/wpcontent/uploads/2017/03/Norms-Paper-2015.pdf

[16] Wiliam, D 2005 Keeping learning on track: Formative assessment and the regulation of learning. Making Mathematics Vital: Proc 20th Biennial Conf of The Aust Assoc of Math Teachers pp $20 \quad-\quad 34$ Retrieved from: https://scholar.google.com.au/scholar?q=Wiliam+ $\% 282005 \% 29 \& \mathrm{hl}=\mathrm{en} \& \mathrm{as} \_\mathrm{sdt}=0 \% 2 \mathrm{C} 5 \& \mathrm{as} \_\mathrm{vis}=1 \&$ as_ylo=2004\&as_yhi=2005 p 21

[17] Foos, P W, Mora, J, and Tkacz, S 1994 Student study techniques and the generation effect. $\mathrm{J} \mathrm{Ed}$ Psych, 864 567-576.

[18] Hiebert, J and Carpenter, T P 1992 Learning And Teaching With Understanding Handbook of Research on Mathematics Teaching and Learning pp 65-97 (ed) D. Grouws (New York: MacMillan)

[19] Sousa, D A 2008 How the brain learns mathematics (Thousand Oaks, CA: Corwin Press) p 56

[20] Skemp, R 1976 Relational understanding and instrumental understanding Mathematics Teaching, $77,20-26$

Skemp, R. (1977). Professor Richard Skemp, interview by Michael Worboys. Mathematics in School, 62 14-15.
Skemp, R 1979 Intelligence, learning and action (Chichester: Wiley \& Sons)

Skemp, R 1986 The psychology of learning mathematics (2nd ed) (London: Penguin Books)

Skemp, R 1989 Mathematics in the primary school (London: Routledge)

Skemp, R. (1992). Bringing theory into the classroom: The school as a learning environment for teachers. In B. Southwell, B. Perry, \& K. Owens (Eds.). Space - The first and final frontier, conf proc, 15 th annual conf of the mathematical education research group of Australia pp 44-54 (UWS Nepean, Sydney: MERGA)

[21] Skemp, R 1976 Relational understanding and instrumental understanding Mathematics Teaching, $77,20-26$

Skemp, R. (1977). Professor Richard Skemp, interview by Michael Worboys. Mathematics in School, 62 14-15.

[22] McFarland, L, Murray, E and Phillipson, S 2016 Student-teacher relationships and student selfconcept: Relations with teacher and student gender.

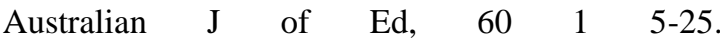
https://doi.org/10.1177/0004944115626426.

[23] Boaler, J. (2015: Revised edition). What's math got to do with it? How teachers and students can transform mathematics learning and inspire success (New York: Penguin Books) p xvii.

[24] Thurston, W 1990 Mathematical education. Notices of the American Mathematical Society, 377844 $850, \mathrm{p} 847$

[25] Dunleavy, T 2018 High School Algebra Students Busting the Myth about Mathematical Smartness: Counter stories to the Dominant Narrative "Get It Quick and Get It Right.” Education Sciences, 8258. MDPI AG. Retrieved from http://dx.doi.org/10.3390/educsci8020058.

[26] Carpenter, T. P and Lehrer, R 1999 Teaching and Learning Mathematics with Understanding Mathematics Classrooms That Promote Understanding pp. 19-32 (eds) E Fennema and T A Romberg (Mahwah, NJ: Lawrence Erlbaum Associates) p 20

[27] Ellerton, N F and Olson, J 2005 The assessment dilemma: Correct answers with no understanding and incorrect answers with some understanding Future directions in science, mathematics and technical education, (Proc 10th Int Conf pp. 226-235 (eds) H. S. Dhindsa, I. J. Kyeleve, O. Chukwu, \& J. 
S. H. Q. Perera (Brunei Darussalam: University Brunei Darussalam)

[28] Vaiyatvutjamai, $\mathrm{P}$ and Clements, M A 2004 Analysing errors made by middle-school students on six linear inequations tasks Globalisation trends in Science, Mathematics and technical Education (Proc 9th Int Conf Dep Science and Mathematics Ed, Universiti Brunei Darussalam, pp 173-182 (Brunei: University Brunei Darussalam) p 181

[29] Wiliam, D 2005 Keeping learning on track: Formative assessment and the regulation of learning. Making Mathematics Vital: Proc 20th Biennial Conf of The Aust Assoc of Math Teachers pp $20 \quad-\quad 34$ Retrieved from: https://scholar.google.com.au/scholar?q=Wiliam+ $\% 282005 \% 29 \& h l=e n \& a s \_s d t=0 \% 2 C 5 \&$ as_vis $=1 \&$ as_ylo=2004\&as_yhi=2005

[30] Black, P J and Wiliam, D 1998 Assessment and classroom learning. Assessment in Education: Principles Policy and Practice, 5 1 7-73.

[31] Sousa, D A 2008 How the brain learns mathematics (Thousand Oaks, CA: Corwin Press)

[32] Leung, F. K. S. (2014). What can and should we learn from international studies of mathematics achievement? Mathematics Education Research Journal, 26(3), 579-605.

[33] White, A L 2011 School mathematics teachers are super heroes South East Asian Mathematics Education J 1 1 3-17

Gilbert, S and White, A L 2018 Innovative Learning in the Age of Industry Revolution 4.0. Southeast Asian Mathematics Education J 81 3-12 ISSN 2089-4716

Although COVID-19 has posted grave challenges for the education system, it provides unique opportunities for digital transformation of education system, creativity and innovated school management and leadership

we move 10 years ahead of time to introduce digital education to the education sector in Cambodia 